\title{
Quantum dot-insect neuropeptide conjugates for fluorescence imaging, transfection, and nucleus targeting of living cells
}

Vasudevanpillai Biju,* Damodaran Muraleedharan, Ken Ichi Nakayama, Yasuo Shinohara, Tamitake Itoh, Yoshinobu Baba, Mitsuru Ishikawa
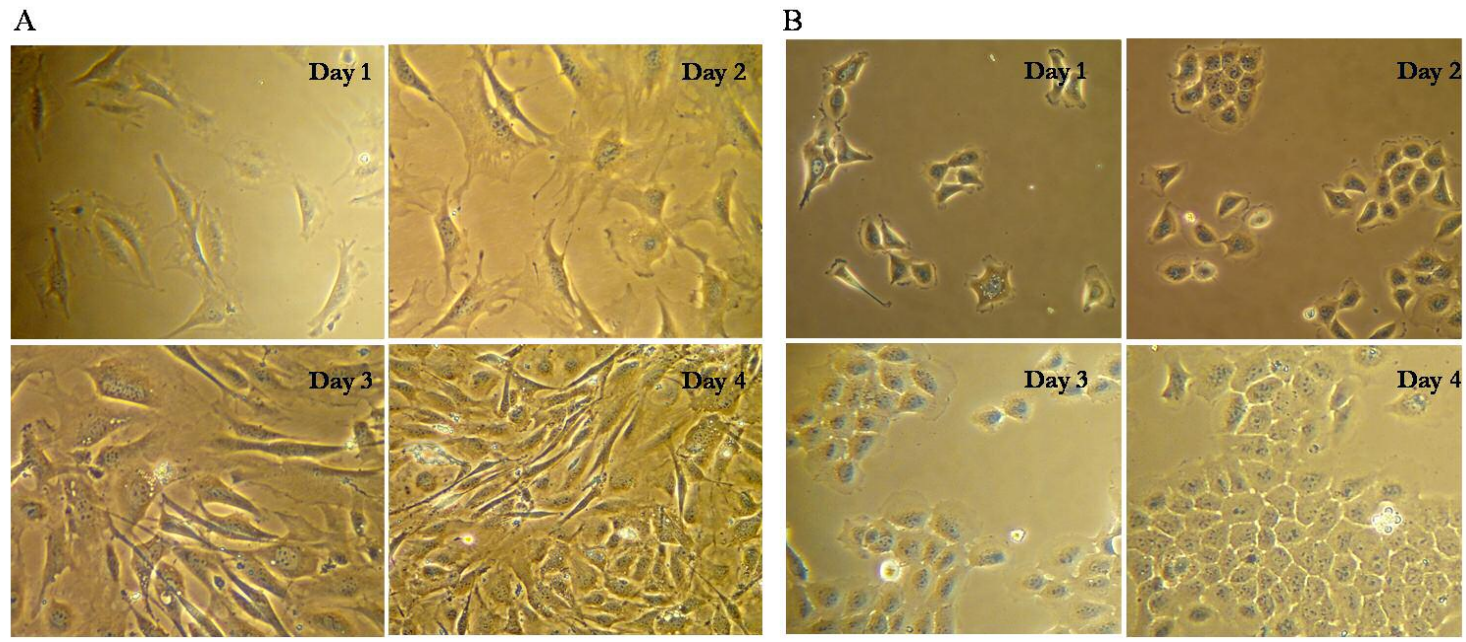

Figure S1. Portions of microphotographs of 3T3 cells (A) and A431 cells (B) under culture in the presence of $38.91 \mathrm{nM}$ allatostatin. The proliferation rates were estimated by analyzing similar microphotographs $(864)$ recorded on $1^{\text {st }}, 2^{\text {nd }}, 3^{\text {rd }}$, and $4^{\text {th }}$ days. 